\title{
KAJIAN USAHA PENGOLAHAN KARET (Hevea brasiliensisL) SIT ASAP RSS (Rubber Smoke Sheet) DI DESA SIMPANG TIGA KECAMATAN MATARAMAN KABUPATEN BANJAR PROVINSI KALIMANTAN SELATAN
}

\author{
(The Study Bussiness Make Rubber Smoke Sheet At Village Simpang Tiga, Mataraman,Banjar \\ Regency Province South Kalimantan)
}

Rohansyah, Subhan Fitriadi, Eddy Triatmoko, Ahmad Ramadhani

Fakultas Pertanian Universitas Achmad Yani Banjarmasin. Rohansyahsamad@gmail.com;babanfitriadi@gmail.com;eddynajhwa@gmail.com; Akhmad Ramadani@gmail.com

Article Submitted : 25-11-2018

Article Accepted : 20-01-2018

\begin{abstract}
The purpose of this research is to know the revenue,the total cost,income and break even point of make Rubber Smoke Sheet farming. This research was conducted in Oktober 2018 at village Simpang Tiga, Mataraman, Banjar regency province South Kalimantan . The Purposive sampling metode used was by observing 23 farmers in Simpang tiga mataraman who.make rubber smoke sheet. The Average result of the revenue is Rp. 5.328.260,87/ farmer, the average total cost is Rp. 2.361.588,27/farmer, and total profit is Rp 2.966.672,60/farmer. BEP Rp. 1.288.984,64dan BEP product Rubber Smoke Sheet 51,56kg/farming. Based on the break even point,we can know the limit result which can give benefit or disvantage. From this result of development of farming make Rubber Smoke Sheet we believe that it has good prospect and revenue, of the break even point ,tecnicall and economically.
\end{abstract}

Key word: Revenue, total cost, income and Break Even point

\section{PENDAHULUAN}

Tanaman karet merupakan salah satu komoditas perkebunan yang berperan penting baik ditinjau dari segi sosial maupun ekonomi. Hal ini karena penyebaran pengusahaannya yang luas dan tersebar diberbagai wilayah serta banyak menyerap tenaga kerja pada berbagai tahap pengelolaan atau kegiatannya. Perkebunan karet rakyat memiliki luas areal yang sangat besar dibandingkan perkebunan besar negara maupun swasta (Dinas Perkebunan,2008 ; 5).

Pembangunan Sektor Perkebunan Kalimantan Selatan sebagai bagian integral dari pembangunan wilayah Propinsi Kalimantan Selatan, dilaksanakannya pembangunan Sektor Perkebunan untuk memperkuat kerangka dasar pondasi pertumbuhan ekonomi, pemerataan pembangunan serta meningkatkan stabilitas dan ketahanan Nasional yang sehat dan dinamis.

Pembangunan Sektor Perkebunan diarahkan tidak hanya pada upaya meningkatkan produksi dan produktivitas semata, tetapi lebih diupayakan pada peningkatan kualitas sumberdaya manusia dan kualitas kehidupan masyarakatnya. Oleh karena itu seluruh kegiatan pembangunan perkebunan lebih menekankan pada pembinaan dan pemberdayaan petani/ masyarakat perkebunan, baik dalam kemampuan menjalankan usaha tani, pemasaran hasil, berkemampuan menerapkan teknologi dan dapat memanfaatkan seoptimal mungkin sumberdaya secara efektif, efisien dan lestari. 
Kabupaten Banjar merupakan salah satu daerah potensial untuk pengembangan komoditas perkebunan yang ada di Kalimantan Selatan. Hal ini dapat dilihat dari luasnya areal perkebunan rakyat yang ada, yaitu mencapai 23.859 Ha (68\%) dan perkebunan besar yang dikelola BUMN (PBN) $10.227,50 \mathrm{Ha}(29 \%)$ maupun swasta (PBS) seluas 842,53 Ha (2,6\%), terdiri dari berbagai komoditas perkebunan, yang meliputi tanaman karet, kelapa sawit, kopi, kelapa dalam, cengkeh lada dan lainnya. Dimana Produksi dan produktivitas Perkebunan Karet Rakyat di Kabupaten Banjar Dari Tanaman Menghasilkan (TM) seluas 15.299 Ha tercatat menghasilkan 12.942.954 kg (846 kg ) per Ha pertahun, Dibanding Perkebunan Besar Negara Produktivitas rata-rata per Ha mencapai 1,3 Ton, Ha/Thn, sedang perkebunan besar swasta mencapai 1,5 ton, Ha/Thn. .(Dinas Pertanian, Perkebunan dan Peternakan, 2018)

Dimasa depan permintaan akan karet alam dan karet sintetik masih cukup signifikan ,karena didorong oleh pertumbuhan industri otomotif yang tentunya memerlukan ban yang berbahan baku karet sintetik dan karet alam (Pedum Ditjenbun Tahun 2015)

Dengan melihat potret potensi dan peluang komoditas karet diatas lalu Dari hasil kajian dan telaahan bersama antara institusi Daerah Provinsi dan Bapenas telah melakukan kajian terhadap produk daerah untuk dijadikan unggulan daerah yang mampu dijadikan sebagai pengembangan ekonomi wilayah secara berkelanjutan di Kabupaten Banjar, sehingga menetapkan komoditas karet sebagai produk unggulan rakyat.

Desa Simpang Tiga terletak di Kecamatan Mataraman Kabupaten Banjar mempunyai topografi tanah datar dan luas yang sebagian besar dimanfaatkan sebagai areal perkebunan rakyat.

Di Desa Simpang Tiga pada umumnya perkebunan yang ada adalah perkebunan karet (Hevea brasilliensis). Di Desa Simpang Tiga produk olahan karet rakyat ada 2 (dua) bentuk yaitu dalam bentuk bokar (Lump, Slab) dan dalam bentuk Sit Asap Karet atau RSS (Rubber Smoke Sheet)yaitu pengolahan karet lembaran, tetapi petani didesa simpang tiga lebih banyak memproduksi dalam bentuk lumb daripada sit asap karet, karena sit asap karet membutuhkan waktu proses pengolah terlebih dahulu baru bisa dipasarkan seadangkan lump langsung bisa dijual akan tetapi dari segi harga, sit asap karet jauh lebih mahal yaitu Rp. 25.000,-per kg dibandingkan lump Rp. 5.000,-per kg.(Dinas Pertanian, Perkebunan dan Peternakan, 2018)

\section{METODE PENELITIAN}

\section{Tempat dan waktu}

Penelitian dilaksanakan di Desa Simpang Tiga Kecamatan Mataraman Kabupaten Banjar Provinsi Kalimantan Selatan yaitu dari bulan Oktober 2018 sampai selesai, yaitu dari tahap persiapan sampai dengan penyusunan laporan.

\section{Metode Penarikan Contoh}

Penelitian ini dilaksanakan dengan metode survei dengan teknik observasi. Penentuan petani responden dilakukan dengan metode Purposive sampling, dimana setiap sampel yang diambil menekankan pada pertimbangan karakteristik tertentu dari subjek tertentu . (Subana dan Sudrajat,2005). Sampel yang diambil yaitu 23 orang yang mengusahakan usahatani pengolahan sit asap karet di Desa Simpang Tiga.

\section{Analisis Data}

Data yang sudah terkumpul diolah dalam bentuk tabulasi dan selanjutnya dianalisa yang meliputi biaya, penerimaan, keuntungan dan Break Even Point (BEP) dari usaha pengolahan sit asap karet. Dalam analisis ini, data yang diperoleh diklasifikasikan menurut jenis dan sifatnya kemudian dihitung sesuai dengan tujuan pengamatan.

Untuk mengetahui besarnya biaya input (sarana produksi) yang digunakan dalam penyelenggaraan usaha pengolahan sit asap 
secara matematis adalah sebagai berikut (Syarifuddin, $1995 ; 70)$ :

$$
\begin{array}{ccc}
\text { TC }= & \text { TFC }+ \text { TVC } \\
\text { Ket : } \quad \text { TC } & =\text { Total Cost / } \\
& \text { Biaya Total (Rp) } \\
& \text { TFC }= & \text { Total Fixed cost } / \\
& \text { Biaya Tetap Total (Rp) } \\
\text { TVC } & \text { Total Variabel Cost / } \\
& \text { Biaya Variabel Total (Rp) }
\end{array}
$$

Untuk mengetahui total penerimaan dirumuskan sebagai berikut (Syarifuddin, 1995)

$$
\mathbf{T R}=\mathbf{P} \times \mathbf{Q}
$$

Ket : $\quad \mathrm{TR}=$ Total Revenue $/$ Penerimaan Total (Rp)

$\mathrm{P}=$ Price $/$ Harga $(\mathrm{Rp})$

$\mathrm{Q}=$ Quantity / Produksi (Kg)

Untuk menentukan besarnya Break Even Point (BEP) pada usaha pengolahan sit asap karet berdasarkan volume produksi dan penjualan (sales) dalam rupiah, secara matematis dapat ditulis dengan rumus (Sukanto,R.H, 1993 ).

$$
\begin{aligned}
& \mathrm{Q}=\frac{F C}{--------} \text { dalam satuan volume }
\end{aligned}
$$

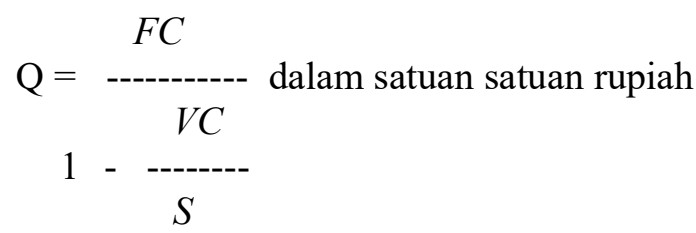

Keterangan :

$$
\begin{aligned}
& \mathrm{Q}=\text { Quantity / jumlah impas } \\
& \mathrm{FC}=\text { Fixed Cost / Biaya Tetap (Rp) } \\
& \mathrm{P}=\text { Price / Harga Persatuan }(\mathrm{Rp} / \mathrm{kg}) \\
& \mathrm{AVC}=\text { Average Variable Cost } / \text { Biaya } \\
& \text { Variabel Rata - rata (Rp) } \\
& \mathrm{VC}=\text { Variable Cost / Biaya Variabel } \\
& \text { (Rp) } \\
& \mathrm{S}=\text { Sales / Penjualan }
\end{aligned}
$$

\section{HASIL DAN PEMBAHASAN}

\section{Aspek Teknis Usaha Pengolahan Sit Asap Karet}

Tempat yang digunakan petani responden untuk mengolah hasil karet adalah Rumah Asap yang berukuran 6 × 4 × 8 meter dan UPH (Unit Pengolahan Hasil) yang berukuran 4 x 5 meter yang berasal dari bantuan APBN dari pemerintah provinsi. Kegiatan pengolahan ini biasanya dilakukan setelah petani mengambil lateks dari perkebunan karet mereka dan lateks tersebut tidak boleh berubah menjadi lump karena jika lateks sudah menjadi lump tidak akan bisa di olah menjadi sit asap lagi. Penjualan hasil produksi sit asap karet ini dilakukan antar pulau.

\section{Produksi}

Produksi yang diperoleh dari usahatani pengolahan sit asap karetdi Desa Simpang Tiga dari 23 petani responden adalah sebesar $4.902,00 \mathrm{~kg} /$ bulan atau rata-rata $213,13 \mathrm{~kg} / \mathrm{petani} /$ bulan. Data lebih terperinci dapat dilihat pada Lampiran 12.

\section{Biaya Penyelenggaraan Usaha PengolahanSit Asap Karet}

Biaya yang dialokasikan petani responden dalam kegiatan usaha pengolahan sit asap yang dikeluarkan meliputi biaya variabel (Variabel Cost) dan biaya tetap (Fixed Cost). Biaya variabel meliputi biaya sarana produksi dan biaya penggunaan tenaga kerja. Sedangkan biaya tetap meliputi biaya penyusutan alat dan bunga modal.

\section{Biaya Variabel \\ Biaya Sarana Produksi}

Biaya sarana produksi meliputi solar, kayu bakar dan asam semut, dari hasil pengolahan data diperoleh biaya penggunaan sarana produksi sebesar Rp. 1.119.290,00 dengan rata-rata Rp. 48.664,78/Petani. Untuk jelasnya lihat Tabel 1. 
Tabel 1. Rata-rata Biaya Sarana Produksi Pada Usaha Pengolahan Sit AsapKaret di Desa Simpang Tiga.

\begin{tabular}{clcc}
\hline No & $\begin{array}{c}\text { Sarana } \\
\text { Produksi }\end{array}$ & $\begin{array}{c}\text { Rata-rata } \\
(\mathrm{Rp})\end{array}$ & $\begin{array}{c}\text { Persentasi } \\
(\%)\end{array}$ \\
\hline 1 & Solar & $14.208,70$ & 29,20 \\
2 & Kayu & $14.208,70$ & 29,20 \\
& Bakar & & \\
3 & Asam & $20.247,39$ & 41,61 \\
& Semut & & \\
\hline Jumlah & & $48.664,78$ & 100,00 \\
\hline
\end{tabular}
Sumber : Hasil Pengolahan Data Primer Tahun 2018.

Dari Tabel 1 diketahui biaya yang terbesar adalah kebutuhan asam semut yaitu sebesarRp. 465.690,00 dengan rata-rata Rp. $14.208,70 /$ petani atau sebesar (41,61\%). Sedangkan biaya yang paling sedikit digunakan sama sedikitnya adalah solar sebesar Rp. 326.800,00 dengan rata-rata Rp. $14.208,70$ /petani atau sebesar $(29,20 \%)$ dan kayu bakar sebesar Rp. 326.800,00 dengan rata-rata Rp. 14.208,70/petani atau sebesar $(29,20 \%)$.

\section{Biaya Tenaga Kerja}

Biaya tenaga kerja yang digunakan meliputi tenaga kerja luar keluarga (TKLK) dan tenaga kerja dalam keluarga (TKDK). Biaya tenaga kerja luar keluarga (TKLK) ratarata sebesar Rp. 325.000,00/petani. Sedangkan biaya tenaga kerja dalam keluarga (TKDK) rata-rata sebesar Rp. 1.290.000,00/petani.

Dari hal tersebut diketahui biaya variabel sebesar Rp. 32.739.290,00 dengan rata-rata sebesar Rp. 1.423.447,39/petani. Data lebih jelas dapat dilihat pada Tabel 2 Pengolahan Sit Asap di Desa Simpang Tiga

Tabel 2. Rata-rata Biaya Variabel Pada Usaha Pengolahan Sit Asap Karetdi Desa Simpang Tiga

\begin{tabular}{llll}
\hline No & Keterangan & Rata-rata (Rp) & Persentase \\
\hline 1 & Sarana & $48.664,78$ & 2,93 \\
2. & $\begin{array}{l}\text { Produksi } \\
\text { Tenaga Kerja }\end{array}$ & $1.615 .000,00$ & 97.07 \\
\hline & jumlah & $1.663 .665,78$ & 100. \\
\hline
\end{tabular}

Sumber : Hasil Pengolahan Data Primer Tahun 2018.
Dari Tabel 2 diketahui biaya terbesar yang dikeluarkan yaitu biaya tenaga kerja (TK) yaitu rata-rata sebesar Rp. 1.615.000,00/petani $(97,07 \%)$, sedangkan biaya terendah pada biaya sarana produksi yaitu sebesar Rp. 48.664,78/petani (2,93\%), hal ini disebabkan pengeluaran biaya atau produksi diperlukan tidak setiap hari.

\section{Biaya Tetap \\ Pajak Lahan}

Biaya pajak lahan mengikuti ketentuan pajak berlaku di Desa Simpang Tiga pada umumnya, perhitungan pajak lahan setiap hasil perhektar dalam satu tahun adalah sebesar Rp. 7.000,-/ha/tahun. Berdasarkan hasil perhitungan maka biaya pajak lahan pada usaha pengolahan sit asap di Desa Simpang Tiga sebesar Rp. 228.760,00 dengan rata-rata sebesar Rp. 9.946,09/petani. Untuk lebih jelasnya mengenai rincian biaya pajak lahan petani responden dapat dilihat pada lampiran 10.

\section{Biaya Penyusutan Alat}

Sehubungan dengan berkurangnya nilai pakai alat-alat produksi pertanian, maka dapat dilakukan perhitungan biaya penyusutan alat-alat yang tahan lama yang mengandung sejumlah nilai pakai yang harus diperhitungkan setiap bulannya. Biaya penyusutan ini tergantung pada nilai alat saat pembelian, usia ekonomis alat, nilai sisa setelah habis jangka ekonomis tersebut (dalam hal ini dianggap nol) dan masa kerja efektif alat dalam masa pengolahan sit asap karet tersebut.

Tabel 3. Biaya Penyusutan Alat Rata-rata Usaha Pengolahan Sit Asap Karetdi Desa Simpang Tiga

\begin{tabular}{clcc}
\hline No & Jenis Alat & Biaya (Rp) & $\begin{array}{l}\text { Persentasi } \\
(\%)\end{array}$ \\
\hline 1 & Kayu & $1.111,11$ & 0,20 \\
& Penjemuran & & \\
2 & Timbangan & $25.000,00$ & 4,50 \\
3 & Pisau Sadap & $1.944,44$ & 0,35 \\
4 & Talang & $11.840,58$ & 2,13 \\
& Sadap & & \\
5 & Mangkok & $88.804,35$ & 15,99 \\
& Lateks & & \\
\hline
\end{tabular}




\begin{tabular}{clcc}
\hline 6 & Loyang & $3.472,22$ & 0,63 \\
& Alumunium & & \\
7 & Ember & $6.557,97$ & 1,18 \\
8 & Mesin & $416.666,67$ & 75,02 \\
& Penggiling & & \\
\hline & Jumlah & $555.397,34$ & 100,00
\end{tabular}

Sumber : Hasil Pengolahan Data Primer Tahun 2018

Dari Tabel 3 diketahui biaya penyusutan alat terbesar yaitu pada biaya mesin penggiling yaitu rata-rata $\mathrm{Rp}$. 416.666,74/petani $(75,02 \%)$, sedangkan biaya terendah pada kayu penjemuran yaitu rata-rata sebesar Rp. 1.111,11 (0,20\%), hal ini disebabkan kayu penjemuran hanya digunakan untuk penjemuran saja.

\section{Bunga Modal}

Bunga modal diperhitungkan dan dimasukkan dalam biaya tetap, karena modal yang digunakan adalah milik petani sendiri. Perhitungan biaya bungan modal adalah dengan jalan mengalikan antara total biaya yang dikeluarkan petani dengan besarnya bunga modal (tingkat suku bunga) yang berlaku saat itu, biasanya bunga modal mengikuti tingkat suku bunga Bank / KUR yang telah disepakati (dalam hal ini adalah 9\%/tahun), sehingga diperoleh rata-rata bunga modal yang dikeluarkan petani sebesar Rp. 17.580,06/petani. Untuk lebih jelasnya dapat dilihat pada Tabel 4

Tabel 4. Rata-rata Biaya Tetap Pada Usaha Pengolahan Sit AsapKaret di Desa Simpang Tiga.

\begin{tabular}{clcc}
\hline No & Biaya Tetap & Biaya (Rp) & $\begin{array}{c}\text { Persentasi } \\
(\%)\end{array}$ \\
\hline 1 & Pajak Lahan & $9.956,09$ & 1,71 \\
2 & $\begin{array}{l}\text { Penyusutan } \\
\text { Alat }\end{array}$ & $555.397,34$ & 95,28 \\
3 & Bunga & $17.580,06$ & 3,02 \\
& Modal & & \\
\hline Jumlah & & $582.933,49$ & 100,00 \\
\hline
\end{tabular}

Sumber : Hasil Pengolahan Data Primer Tahun 2018

Pada Tabel 4 diketahui biaya tetap yang terbesar dari usaha pengolahan sit asap karet di Desa Simpang Tiga selama adalah biaya penyusutan alat yaitu sebesar Rp. $555.397,34(95,28 \%)$, sedangkan yang terkecil berupa biaya pajak lahan yaitu sebesar Rp. 9.956,09 (1,71\%) dari keseluruhan biaya tetap pada usaha pengolahan sit asap karet, hal ini disebabkan pajak lahan dibayar hanya satu kali setahun.

\section{Biaya Total}

Biaya total dalam penelitian ini merupakan penjumlahan dari biaya tetap (FC) dengan biaya variabel (VC) biaya total pada usaha pengolahan sit asap karet sebesar Rp. $54.316 .530,31$ atau rata-rata sebesar $\mathrm{Rp}$. 2.361.588,27/petani. Untuk jelasnya dapat dilihat pada Tabel 5

Tabel 5. Rata-rata Biaya Total Pada Usaha Pengolahan Sit AsapKaret di Desa Simpang Tiga

\begin{tabular}{|c|c|c|c|}
\hline No & Uraian Biaya & $\begin{array}{l}\text { Rata-Rata } \\
\text { Biaya (Rp) }\end{array}$ & $\begin{array}{c}\text { Persentase } \\
(\%)\end{array}$ \\
\hline 1 & $\begin{array}{l}\text { Biaya } \\
\text { Variabel } \\
\text { (VC) }\end{array}$ & $1.423 .447,39$ & 60,28 \\
\hline 2 & $\begin{array}{l}\text { Biaya Tetap } \\
(\mathrm{FC})\end{array}$ & $938.140,88$ & 39,72 \\
\hline & Jumlah & $2.361 .588,27$ & 100,00 \\
\hline
\end{tabular}

Sumber : Hasil Pengolahan Data Primer Tahun 2018

Pada Tabel 5 diketahui biaya variabel (VC) rata-rata sebesar Rp. 1.423.447,39 $(60,28 \%)$. Sedangkan biaya tetap rata-rata sebesar Rp. 938.140,88/petani (39,72\%). Dengan demikian dapat disimpulkan bahwa besar kecilnya produksi yang diperoleh petani responden pada usaha pengolahan sit asap karet sangat ditentukan oleh besar kecilnya biaya yang dikeluarkan petani terutama untuk biaya variabel.

\section{Penerimaan}

Penerimaan yang dihasilkan pada usahatani pengolahan sit asap karet di Desa Simpang Tiga berupa sit asap karet sejumlah $4.902,00 \mathrm{~kg}$ rata-rata $213,13 \mathrm{~kg} /$ petani dengan harga Rp. 25.000,00/kg. Besar penerimaan yang diperoleh petani sebesar Rp. 122.550.000,00 dengan rata-rata $\mathrm{Rp}$. 5.328.260,87/petani.

Besar kecilnya penerimaan yang diperoleh petani responden tidak terlepas dari pengolahan usahataninya yaitu menggunakan faktor input (sarana produksi, tenaga kerja, 
modal dan keterampilan) lebih efektif guna mendapatkan produksi yang optimal. Namun demikian penerimaan juga dipengaruhi oleh tinggi rendahnya output (produksi), karena pada umumnya harga output sering juga terjadi fluktuasi.

\section{Keuntungan}

Keuntungan adalah hasil pengurangan antara total penerimaan dengan total biaya yang dikeluarkan petani dalam satu bulan proses produksi. Rata-rata keuntungan yang diperoleh petani adalah sebesar $\mathrm{Rp}$. 2.966.672,60/petani.

\section{Analisis Break Event Point Usaha Pengolahan Sit Asap Karet}

Analisis Break Event Point (BEP) adalah salah satu analisis ekonomi yang berguna untuk menentukan besarnya kuantitas produksi suatu unit usaha agar dapat memeperhitungkan keuntungan yang diharapkan sehinggal petani dapat mempertimbangkan kelanjutan usaha yang sedang dijalankan. Dengan perkataan lain bahwa petani haruslah mengetahui produksi diatas titik impas terjadi, sehingga apabila produksi di atas titik impas tentu akan memperoleh keuntungan sesuai dengan seberapa jauh dia mampu berproduksi di atas titi impas tersebut.(Soekartawi,2000)

Dari hasil pengolahan data, nilai Break Event Point (BEP) dilihat dari volume produksi sebesar 51,56 kg/petani dan dari jumlah penerimaan atau hasil penjualan sebesar Rp 1.288.984,64/petani, artinya usaha pengolahan sit asap karet sudah bisa impas dengan nilai TR-nya sebesar Rp. 1.288.984,64 dan produksi 51,56kg. Apabila nilai TR-nya sebesar Rp. 5.328.260,87 dan produksi $213,13 \mathrm{~kg}$, maka usahatani tersebut menguntungkan.

Break even poin atau titik impas dalam rupiah dapat diketahui dengan mengkonversi harga jual per unit dikalikan jumlah yunit yang terjual (Zulifah dan Norhalimah, 2017)

Pada usaha pengolahan sit asap di Desa Simpang Tiga, ternyata TR lebih besar dari TC, sehingga usaha ini telah menguntungkan terlihat dari nilai TR hasil produksi sebesarRp. 5.328.260,87/petani lebih besar dari nilai BEP, yaitu sebesar Rp. 1.288.984,64/petani atau bila dilihat dari volume produksi, nilai BEP produksi sit asap sebesar $51,56 \mathrm{~kg} /$ petani, hal ini dapat dilihat volume produksi, yaitu $213,13 \mathrm{~kg} /$ petani berada diatas nilai BEP. Secara grafis titik BEP dapat dilihat pada Gambar 1 berikut ini

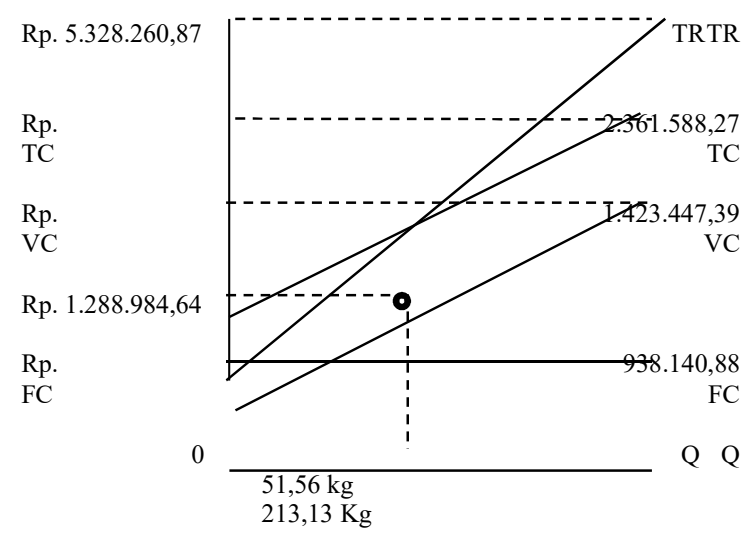

Gambar 1. Kurva Break Event Point (BEP) Pada Usaha Pengolahan Sit Asap Karet di Desa Simpang Tiga

Pada gambar diatas diketahui usaha pengolahan karet diperoleh nilai rata-rata Break Event Point (BEP) sebesar $51,56 \mathrm{~kg} /$ petani dilihat dari volume produksi dan hasil penjualan (penerimaan) sebesar Rp. 1.288.984,64/petani dengan demikian telah mampu melewati nilai Break Event Point (BEP), sebab bila dilihat dari rata-rata penerimaan atau produksi pada usaha pengolahan sit asap selama proses produksi di Desa Simpang Tiga telah mampu menghasilkan keuntungan sehingga perlu dikembangkan lebih lanjut atau dioptimalkan produksinya. Data lebih rinci tentang rata-rata penerimaan, rata-rata keuntungan dan Break Event Point (BEP) pada usaha pengolahan sit asap karet dapat dilihat pada Tabel 6 . 
Tabel. 6. Rata-rata Penerimaan, Rata-rata Keuntungan dan Break Event Point (BEP)

\begin{tabular}{clc}
\hline No & \multicolumn{1}{c}{ Uraian } & Jumlah \\
\hline 1 & $\begin{array}{l}\text { Rata-rata Penerimaan } \\
(\mathrm{TR})\end{array}$ & Rp. 5.328.260,87 \\
2 & $\begin{array}{l}\text { Rata-rata Keuntungan } \\
(\pi)\end{array}$ & Rp. 2.966.672,60 \\
3 & $\begin{array}{l}\text { Break Event Point } \\
(\text { BEP) }\end{array}$ & \\
& $-\quad$ Rata-rata Volume & $51,56 \mathrm{~kg}$ \\
& $-\quad \begin{array}{l}\text { Produksi } \\
\text { Rata-rata }\end{array}$ & Rp. 1.288.984,64 \\
\hline
\end{tabular}

Berdasarkan hasil penelitian dan perhitungan bahwa produksi, penerimaan, keuntungan dan nilai Break Event Point (BEP) adalah selama satu kali proses produksi dengan demikian diasumsikan bahwa seluruh perhitungan dan hasil yang diperoleh untuk satu kali proses produksi tersebut untuk keperluan hidup petani dan keluarganya selama 1 bulan (30 hari)

\section{KESIMPULAN DAN SARAN}

\section{Kesimpulan}

Berdasarkan hasil pengamatan dilapangan dan analisis data primer mengenai usahatani pengolahan sit asap karet karet di Desa Simpang Tiga Kecamatan Mataraman, maka dapat kesimpulan sebagai berikut :

1. Secara teknis penyelenggaraan usahatani pengolahan karet di Desa Simpang Tiga dilakukan secara baik dan benar sesuai dengan teknis yang dianjurkan Dinas Pertanian, Perkebunan dan Peternakan Kabupaten Banjar yaitu untuk pembeku asam semut rata-rata $0,75 /$ ha.

2. Secara ekonomis usahatani pengolahan karet di Desa Simpang Tiga bahwa biaya variabel rata-rata sebesarRp. 1.423.447,39/petani sedangkan biaya tetap rata-rata sebesar Rp. 938.140,88/petani. Total biaya rata-rata adalah Rp. 2.361.588,27/petani. Penerimaan yang diperoleh petani ratarata sebesar Rp. 5.328.260,87/petani.
3. Jumlah produksi berupa sit asap karet sejumlah 4.902,00 kg rata-rata 213,13 $\mathrm{kg} /$ petani

4. Harga yang berlaku Rp. 25.000/kg. Jumlah penerimaan yang diperoleh petani sebesar Rp. 122.550.000,00 dengan ratarata sebesar Rp. 5.328.260,87/petani. Rata-rata keuntungan yang diperoleh petani dalam satu bulan proses produksi adalah sebesar Rp. 2.966.672,60/petani.

5. Dilihat dari volume produksi sebesar $51,56 \mathrm{~kg} /$ petani dan dari jumlah penerimaan atau hasil penjualan sebesar Rp. 5.328.260,87/petani. Diketahui TR lebih besar dari TC, yaitu sebesar Rp. 5.328.260,87/ petani nilai tersebut lebih besar dari nilai BEP Rp. 1.288.984,64/ petani atau bisa dilihat dari volume produksi, nilai BEP produksi sit asap karet sebanyak $51,56 \mathrm{~kg} /$ petani, diatas nilai volume produksi yaitu 213,13 $\mathrm{kg} /$ petani. Dengan mengetahui batasan nilai tersebut, sehingga kita dapat mengetahui ukuran kemugkinan titik impas, keuntungan dan kerugian suatu usaha ini.

\section{Saran}

Berdasarkan hasil penelitian ini, dapat disarankan beberapa hal sebagai berikut :

1. Agar pendapatan lebih meningkat lagi maka perlu diintensifkan lagi usahatani yang diusahakan.

2. Dengan mengetahui titik impas atau pun kembli modal (BEP),sebaiknya petani harus bisa mengatur dan mengefisiensikan faktor produksinya, guna mendapatkan keuntungan yang lebih baik.

3. Untuk menjaga kestabilan harga jual sit asap asap maka perlu peran pemerintah untuk mengatur harga dengan pembentukan Lembaga Khusus Pengawasan harga karet hingga di pedesaan ataupun mengendalikan harga sit asap dipasaran, sehingga petani tidak dirugikan. 


\section{DAFTAR PUSTAKA}

Dinas Perkebunan. 2008, Provinsi Kalimantan Selatan.

Dinas Pertanian, Perkebunan dan Peternakan. 2014, Petunjuk Teknis Pengolahan Sit Asap Karet. Kabupaten Banjar.

Direktorat Jendral Perkebunan, 2015. Pedoman teknis Pengembangan Tanaman Karet. Jakarta

M. Subana, dan Sudrajat, 2005.Dasar - Dasar Penelitian Ilmiah, Pustaka Setia Bandung.

Soekartawi, 2000. Agribisnis. Teori dan Aplikasinya, PT. Agromedia Pustaka Jakarta.
Sukanto Reksohadi Pradjo, 1985.

Manajemen Edisi 5, (Yogyakarta: BPFE)

Syarifudin A. Kasim. 1995, Pengatan Ekonomi Produksi Pertanian. Lambung Mangkurat Universitas. Banjarbaru.

Zulifah Mahdalena dan Norhalimah, 2017. Analisis Titik Impas Usahatani Tanaman Ketepeng Cina (Cassia alata L) Pada PT Srikaya Sega Utama Banjarbaru.Jurnal Ziraa'ah Volume 42 nomor 3 oktober 2017 ISSN Elektronik 2355-3545 UNISKA Banjarmasin. 